\title{
Formulation Development of Stronger and Quick Disintegrating Tablets: A Crucial Effect of Chitin
}

\author{
Honey Goel, Gurpreet KaUR, Ashok K. TIWARY, and Vikas RANA* \\ Pharmaceutics Division, Department of Pharmaceutical Sciences and Drug Research, \\ Punjabi University, Patiala 147002, Punjab, India
}

(Received October 5, 2009; Accepted December 22, 2009)

\begin{abstract}
A well known superdisintegrant like croscarmellose sodium or crospovidone loses their quick disintegration property when compressed at more than $4 \mathrm{~kg}$ tablet crushing strength (TCS). Therefore, the objective of the present work was to develop a disintegrating system that could be used for preparing fast disintegrating tablets (FDTs) of highly water soluble drug, metoclopramide, without compromising on the mechanical strength, irrespective of the TCS used for compressing the granules. For this purpose disintegrating system consisting of chitosan-alginate (CTN-ALG) complex (1 : 1): glycine and chitin was developed. The results revealed that when CTN-ALG and glycine were mixed in the ratio of $30: 70$, the granules exhibited a minimum water sorption time and maximum effective pore radius $\left(\mathrm{R}_{\text {eff.p }}\right)$. The addition of chitin $(5-10 \% \mathrm{w} / \mathrm{w})$ into this mixture further enhanced the $\mathrm{R}_{\text {eff.p }}$. Further, increase in the concentration of chitin from $10 \%$ to $20 \% \mathrm{w} / \mathrm{w}$ did not produce any significant effect $(p>0.05)$ on the $\mathrm{R}_{\text {eff.p }}$. The FDTs prepared by using CTNALG : glycine $(30: 70)$ and chitin exhibited increased porosity and lower disintegration time (DT). Further, chitin was found to neutralize the effect of TCS on DT of FDTs. This property of chitin was also observed in FDTs prepared by using croscarmellose sodium $(5 \% \mathrm{w} / \mathrm{w})$ or crospovidone $(5 \% \mathrm{w} / \mathrm{w})$. The reduction in DT of FDTs by chitin was also observed in tablets prepared without the drug. Hence, the effect was not influenced by the solubility component present in the tablets. Overall, the results suggested incorporation of chitin $(5-10 \% \mathrm{w} / \mathrm{w})$ while preparing FDTs of metoclopramide to enhanced the disintegration without compromising their mechanical strength of the tablets.
\end{abstract}

Key words_— fast disintegrating tablet; glycine; chitosan-alginate complex; chitin; metoclopramide $\mathrm{HCl}$

\section{INTRODUCTION}

Direct compression method is inexpensive, most convenient and produces tablets of sufficient mechanical integrity without the use of complicated unit operations. ${ }^{1)}$ However, the disintegration of FDTs prepared by direct compression method is often compromised while improving the mechanical strength of tablets. Superdisintegrants like croscarmellose sodium, crospovidone and sodium starch glycolate can disintegrate the tablets faster. However, they are of limited use when tablets are prepared with crushing strength of more than $4 \mathrm{~kg}^{2}{ }^{2}$ Also, microcrystalline cellulose (Avicel- PH101 \& PH102) or dicalcuim phosphate added in FDTs for enhancing their disintegration often cause unpleasant feeling of grittiness in mouth. Attempts aimed at using amino acids in combination with carmellose for preparing FDTs with sufficient mechanical strength by direct compression have not been found suitable for water soluble drugs like ondansetron $\mathrm{HCl}^{3}{ }^{3,4}$ Hence, there is a need

*e-mail: vikas_pbi@rediffmail.com to develop an alternative sweet tasting disintegrating system for preparing FDTs for water soluble drugs having sufficient mechanical strength and quick disintegration that is independent of tablet crushing strength (TCS).

Chitin $(\beta$ - $(1 \rightarrow 4)-\mathrm{N}$-acetyl-D-glucosamine $)$ is a natural polysaccharide obtained from crab and shrimp shells. It possesses amino group covalently linked to acetyl group as compared to free amino group in chitosan. ${ }^{5,6)}$ Bruscato and Danti ${ }^{7)}$ reported that when chitin was included in the conventional tablets, the tablets disintegrated within 5-10 min irrespective of solubility of the drug. Further, the disintegration time in the oral cavity (DT) as well as wetting time (WT) could be compared with surface free energy. ${ }^{2)}$ For faster wetting, a molecule should have high polar component of surface free energy. However, for faster disintegration, the dispersion component should have larger value. Therefore, it seems essential to select additives possessing wicking, swelling and disintegrating properties for successful performance of FDTs containing water soluble drugs.

Metoclopramide hydrochloride is an antiemetic 
agent. It is used for the prophylaxis of vomiting associated with cisplatin or other chemotherapeutic agents. The drug is highly soluble in water and is rapidly absorbed after oral administration. ${ }^{8-10)}$ It has a short biological half life and is usually administered in a dose of $10-15 \mathrm{mg}$ four times a day to maintain effective concentration throughout the day. Rapid action of metoclopramide is not achievable by administering it in conventional tablet form. In addition, swallowing conventional tablets requires considerable quantity of water, which is often difficult for patients suffering from vomiting. Hence, FDTs of metoclopramide seem to offer distinct advantage over its conventional tablet form in terms of ease of administration and enhanced pre-gastric absorption, thereby ensuring immediate effect.

In the light of the above, the present investigation was aimed at development and evaluation of disintegration system that is suitable for FDTs having sufficient mechanical strength as well as quick disintegration time. The study involves screening of a combination of swellable biodegradable polymeric mixture (chitosan-alginate complex : glycine) and tablet strength enhancer (chitin) for developing FDTs containing a water soluble drug $(1.5 \mathrm{gm} / \mathrm{ml})$, metoclopramide $\mathrm{HCl}$. Further, the effect of chitin in FDTs was also evaluated and compared with known superdisintegrants.

\section{MATERIAL AND METHODS}

Materials Metoclopramide $\mathrm{HCl}$ (99.9\% Nayan Pharmaceuticals Ltd, Patiala, Punjab, India) crospovidone and croscarmellose sodium (Panacea Biotech Ltd. Lalru, India) were received as gift samples. Chitosan (Indian Sea Foods, Cochin, India), chitin (Himedia Laboratories Pvt. Ltd., Mumbai, India), glycine (Qualigens Fine Chemicals, Mumbai, India), n-hexane (Loba Chemi, Mumbai, India) and spray dried lactose (CDH, Mumbai, India) were used as supplied. All other reagents were of analytical grade.

\section{Methods}

Preparation of Chitosan-alginate Complex (CTNALG) The CTN-ALG was prepared by coacervation-phase separation method. Chitosan solution was prepared by dissolving chitosan $(3.0 \% \mathrm{w} / \mathrm{v})$ in $20 \mathrm{ml}$ of $2 \% \mathrm{v} / \mathrm{v}$ acetic acid. Separately, a solution of sodium alginate $(4.0 \% \mathrm{w} / \mathrm{v})$ in $20 \mathrm{ml}$ of distilled water was prepared. Chitosan solution was added to alginate solution dropwise with constant stirring $(1000 \mathrm{rpm})$. Isopropyl alcohol $(150 \mathrm{ml})$ was then added to completely separate chitosan-alginate interpolymer complex. The washed CTN-ALG was dried in oven $\left(50^{\circ} \mathrm{C}, 48 \mathrm{~h}\right)$ followed by microwave drying $(85 \mathrm{~W}, 10 \mathrm{~s})$ to remove any bound water and then sieved (\#22) to obtain powder of uniform size.

Preparation of Metoclopramide FDTs by Direct Compression Glycine (40-60\% w/w), chitin (5$30 \% \mathrm{w} / \mathrm{w})$ and CTN-ALG complex $(5-15 \% \mathrm{w} / \mathrm{w})$ or chitin $(5-20 \% \mathrm{w} / \mathrm{w})$, colloidal silica $(0.5 \% \mathrm{w} / \mathrm{w}$, as lubricant) and superdisintegrant (croscarmellose (5 $\% \mathrm{w} / \mathrm{w})$ or crospovidone $(5 \% \mathrm{w} / \mathrm{w}))$ were mixed in dry state. To this mixture, spray dried lactose (q.s) and metoclopramide $\mathrm{HCl}(10 \% \mathrm{w} / \mathrm{w})$ were added and blended by tumbling for $30 \mathrm{~min}$. The resulting blend was compressed into tablets with a multipunch six station rotary tableting machine (A. K. Industries, Nakodar, Punjab, India). The average weight and diameter of round shaped FDT was $100 \pm 5 \mathrm{mg}$ and $6 \pm$ $0.5 \mathrm{~mm}$, respectively.

Evaluation of Powder Blends Pure excipients alone or their combinations in dry state were subjected to estimation of water sorption time, effective pore radius and swelling index.

Water Sorption Time (WST) and Swelling Index (SI) The sample $(250 \mathrm{mg})$ was filled into micropipette tips (transparent, $2 \mathrm{ml}$ ) for estimating WST and SI. The tip outlet was first blocked with a tiny swab of Nylon fiber to avoid leakage of the powder. After placing the solid sample into the tip, it was tapped 10 times by dropping on a hard surface from $10 \mathrm{~cm}$ height to obtain approximately the same packing. The plastic tip was weighed $\left(\mathrm{W}_{\mathrm{a}}\right)$ then dipped into a 2-3 mm layer of phosphate buffer $\mathrm{pH}$ 6.8. The time taken by the liquid to reach to the top of the powder bed was estimated as WST. The filled tip was again weighed $\left(\mathrm{W}_{\mathrm{b}}\right)$ at the end of the experiment. The $S I$ was estimated as

$$
S I=\mathrm{W}_{\mathrm{b}}-\mathrm{W}_{\mathrm{a}} / \mathrm{W}_{\mathrm{a}} \times 100
$$

The experiments were repeated six times and average values were taken for calculation.

Effective Pore Radius ( $\left.\mathbf{R}_{\text {eff.p }}\right) \quad \mathbf{R}_{\text {eff.p }}$ of the powder blend was estimated according to the method reported by Chibowski et al. ${ }^{11)}$ In brief, the micropipette tip ( $2 \mathrm{ml}$, transparent) was filled with the powder and weighed $\left(\mathrm{W}_{\mathrm{A}}\right)$. Then $\mathrm{n}$-hexane [surface tension $(\gamma) \quad 18.4 \mathrm{mN} / \mathrm{m}$ ] was poured dropwise on the bedtop till the solvent filtered out at the bottom 
of the tip. The tip was weighed again $\left(\mathrm{W}_{\mathrm{B}}\right)$. The experiments were repeated six times.

$$
\mathrm{R}_{\text {eff. } \mathrm{p}}=\mathrm{W}_{\mathrm{B}}-\mathrm{W}_{\mathrm{A}} / 2 \pi \gamma
$$

\section{Evaluation of FDTs}

Tablet Crushing Strength Texture analyzer (TAXT plus, Stable Microsystems, UK) was used to measure the hardness of tablets. The tablet tensile strength is the force required to break a tablet by compressing it in the radial direction. For measuring the hardness of the tablets, the texture analyzer was adjusted to compression mode. The other parameters included: $0.5 \mathrm{~mm} / \mathrm{s}$ pretest speed, force target mode with $50 \mathrm{~g}$ force at a holding time of $60 \mathrm{~s}$. Tablet crushing strength $(\mathrm{T})$ was calculated using the formula:

$$
\mathrm{T}=2 \mathrm{~F} / \pi \mathrm{dt}
$$

Where ' $F$ ' is the crushing load and ' $\mathrm{d}$ ' and ' $\mathrm{t}$ ' denote the diameter and thickness of the tablet, respectively.

The data reported is the mean of six individual determinations.

Tablet Porosity The tablet porosity was calculated using the equation,

$$
\varepsilon(\%)=(1-\mathrm{M} / \mathrm{V} \rho) * 100
$$

where $\rho$ is true density, $\mathrm{M}$ and $\mathrm{V}$ are, respectively, the tablet weight and tablet volume. The diameter and thickness of tablet for calculating $\mathrm{M}$ and $\mathrm{V}$ were measured using micrometer. The true density of the powder was determined using a pycnometer. The experiments were repeated six times.

Weight Variation The weight variation test was performed on randomly collected 20 tablets from a batch of 100 tablets according to the method specified in USP30NF25.

Content Uniformity Thirty tablets were randomly selected from each batch and 10 tablets were analyzed individually. The amount of metoclopramide $\mathrm{HCl}$ was analyzed at $320 \mathrm{~nm}$ in $0.1 \mathrm{~N} \mathrm{HCl}$ (Beckman DU-640B UV/VIS) .

In Vivo Disintegration Time (DT) The in vivo DT was assessed in six healthy male volunteers for each batch of tablets. ${ }^{12}$ The volunteers were informed of the protocol and purpose of the study. All the volunteers were asked to rinse their oral cavity with distilled water prior to the test. Each volunteer was asked to place one tablet on the tongue and a stopwatch was started immediately. The volunteers were given strict instructions not to chew or swallow the tablets, although licking was allowed. The end point of disintegration in the oral cavity was meas- ured as the time when the tablet placed on the tongue disintegrated without leaving any lumps. All the volunteers were instructed to rinse their mouth after completion of test.

\section{RESULTS AND DISCUSSION}

Disintegrant addition is one of the popular techniques for formulating FDTs whereby optimum concentrations of superdisintegrants are added to the formulation to achieve quick disintegration accompanied with good mouth feel. The literature reports revealed the use of relatively expensive semisynthetic polymeric superdisintegrants like crosspovidone, croscarmellose sodium, sodium starch glycollate, PVPK12 and crosslinked sodium carboxy methylcellulose. ${ }^{13)}$ However, these semisynthetic superdisintegrants failed to disintegrate quickly when compressed at higher tablet crushing strength. ${ }^{14-15)}$ Therefore, an attempt was made to develop a disintegrating system for FDTs that would exhibit fast disintegration even when prepared at high compression force.

Preliminary studies were conducted to evaluate FDTs. Only those batches of FDTs were included in the study that passed the tests for weight variation, friability and content uniformity according to the limits as specified in the USP30NF25.

Development of Disintegrating System WST, $\mathrm{R}_{\text {eff.p }}$ and $S I$ of individual excipients or their combination were evaluated for investigating their role in the disintegration of FDTs (Fig. 1). WST indicates the rate at which water gets transported through the powder bed, $R_{\text {eff.p }}$ is an indicator of porosity of powder and $S I$ indicates swelling nature of powder. Buffer $\mathrm{pH}$ 6.8 was found to wet the CTN-ALG complex in $115 \pm$ $4 \mathrm{~s}$, suggesting poor wicking property of CTN-ALG complex. However, it had an SI of $17.69 \%$ which indicated its good swelling property. Glycine was found to exhibit excellent wetting as it was wetted by buffer pH 6.8 in $32 \mathrm{~s}$ and the powder was porous in nature. But, the glycine powder exhibited $S I$ of $5.93 \%$ indicating less water holding capacity. When CTNALG complex was mixed with glycine, the WST drastically decreased to $12 \pm 1 \mathrm{~s}$. The WST was reduced by 10.7 -fold as compared to that of CTNALG alone. Also, glycine increased the $\mathrm{R}_{\text {eff.p }}$ of CTNALG by 1.6-fold. Further, increasing the concentration of glycine in the GLY, CTN-ALG mixture increased the $\mathrm{R}_{\text {eff.p }}$ and decreased the WST (Fig. 1). On the other hand, decreasing the concentration of CTN- 


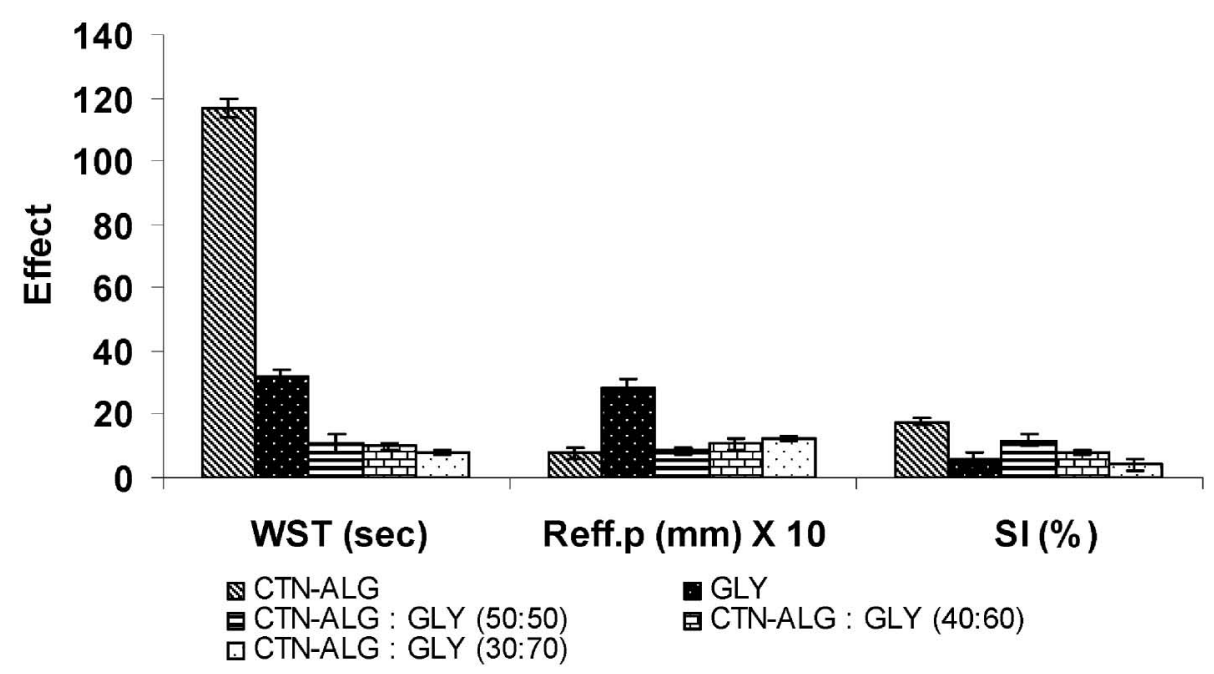

Fig. 1. Effect of Mixture Containing CTN-ALG and Glycine on Water Sorption Time (WST), Effective Pore Radius (R $\mathrm{R}_{\text {eff.p }}$ ) and Swelling Index $(S I)$

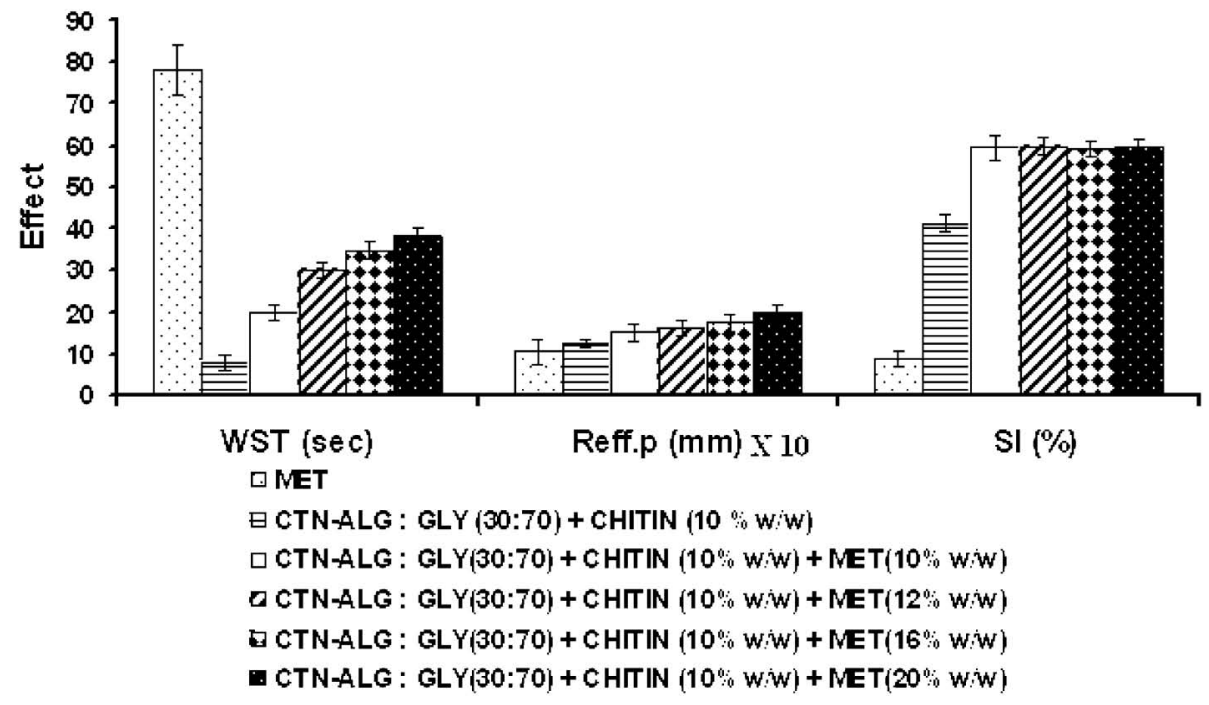

Fig. 2. Effect of Various Concentrations of Metoclopramide $\mathrm{HCl}$ on Water Sorption Time (WST), Effective Pore Radius ( $\mathrm{R}_{\text {eff.p }}$ ) and Swelling Index $(S I)$

ALG complex in the GLY, CTN-ALG mixture decreased the SI. Therefore, these results are a pointer towards the ability of glycine to reduce the WST of CTN-ALG and hence, its pivotal role in transporting aqueous medium to different parts of the tablet due to wicking action and porosity enhancing property. Further, these two properties of glycine were observed to be operative in tablets compressed to high crushing strengths. Therefore, an increase in concentration of CTN-ALG increased the swelling action which led to reduced DT. Hence, it seems logical to expect that glycine created aqueous channels, which enhanced the transport of water to CTN-ALG, eventually resulting in swelling of the tablets. Therefore, it could be postulated that CTN-ALG complex and glycine $(30: 70)$ (showing minimum WST and maximum $R_{\text {eff.p }}$ ) could be successfully used for decreasing the DT.

Effect of Metoclopramide $\mathrm{HCl}$ on DT The WST of metoclopramide $\mathrm{HCl}$ powder in buffer $\mathrm{pH}$ 6.8 was $78 \mathrm{~s}$ at its $R_{\text {eff.p }}$ of $1.062 \pm 0.04 \mathrm{~mm}$ (Fig. 2). The addition of increasing concentration of metoclopramide $\mathrm{HCl}$ to a mixture containing CTNALG : GLY (30:70) and chitin $(5 \% \mathrm{w} / \mathrm{v})$ increased the WST as well as $R_{\text {eff.p. }}$. However, it did not affect the SI. This indicated that metoclopramide $\mathrm{HCl}$ antagonized the wicking action of glycine. This could be attributed to the high aqueous solubility of 
metoclopramide $\mathrm{HCl}$. The water penetrated initially during disintegration process shall rapidly produce a solution in the core of FDT. As a consequence, additional water is not expected to get transported into the core of the FDTs. This possibly led to delayed disintegration of tablets. Therefore, all the FDTs were prepared using adult dose of metoclopramide $\mathrm{HCl}(10$ $\mathrm{mg}$ ) which amounted to $10 \% \mathrm{w} / \mathrm{w}$ of the total tablet weight.

Effect of Chitin on DT Chitin (a copolymer of $\mathrm{N}$ acetyl-glucosamine and $\mathrm{N}$-glucosamine) is reported to act as disintegrant and exhibits less DT as compared to starch. ${ }^{7)}$ The effect of increasing concentration of chitin on porosity of FDTs compressed at different crushing strengths was investigated (Fig. 3). The results revealed that chitin increased the porosity of FDTs (Fig. 3). However, no significant $(p<0.05)$ effect on tablet porosity was observed when concentration of chitin was increased beyond $20 \% \mathrm{w} / \mathrm{w}$, irrespective of the TCS of FDTs. Further, the incorporation of $5 \% \mathrm{w} / \mathrm{w}$ to $20 \% \mathrm{w} / \mathrm{w}$ concentration of chitin in the FDTs made it possible to prepare FDTs even at crushing strength of $7 \mathrm{~kg}$ (Fig. 3).

It is important to note that the DT of FDTs pre- pared at the highest crushing strength of $7 \mathrm{~kg}$ was not significantly $(p>0.05)$ different from those prepared at lower crushing strengths. Conventional logic implies greater DT for tablets prepared at higher crushing strength. Table 1 indicates that increasing the concentration of chitin from $5 \% \mathrm{w} / \mathrm{w}$ to $20 \% \mathrm{w} / \mathrm{w}$ in presence of a mixture of CTN-ALG : GLY (30:70) powder blend did not affect $S I$. However, the $\mathrm{R}_{\text {eff.p }}$ was observed to increase while WST was observed to decrease. This indicated that the decrease in DT of

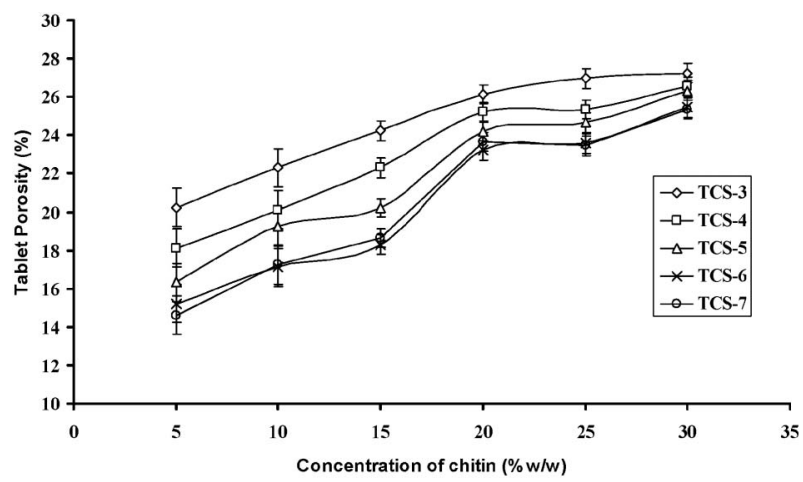

Fig. 3 Effect of Concentration of Chitin on Disintegration Time (DT) and Tablet Porosity (TP) of Tablets Compressed at Different Tablet Crushing Strength

Table 1. Effect of Chitin When Present with Different Disintegrant Systems on Powder Characteristics

\begin{tabular}{|c|c|c|c|c|c|c|}
\hline \multirow{2}{*}{$\begin{array}{l}\text { Formulation } \\
\text { code }\end{array}$} & \multirow{2}{*}{$\begin{array}{c}\text { Disintegrant system } \\
(\% \mathrm{w} / \mathrm{v})\end{array}$} & \multirow{2}{*}{$\begin{array}{l}\mathrm{MET} \\
(\mathrm{mg})\end{array}$} & \multirow{2}{*}{$\begin{array}{l}\text { Chitin } \\
(\% \mathrm{w} / \mathrm{v})\end{array}$} & \multicolumn{3}{|c|}{ Powder Characteristics } \\
\hline & & & & $\begin{array}{l}\text { WST } \\
(\mathrm{s})\end{array}$ & $\begin{array}{l}S I \\
(\%)\end{array}$ & $\begin{array}{l}\mathrm{R}_{\text {eff.p }} \\
(\mathrm{mm})\end{array}$ \\
\hline Control-1 & \multirow{5}{*}{$\begin{array}{c}\text { Chitosan-alginate : glycine } \\
(30: 70)\end{array}$} & 10 & - & $20 \pm 1$ & $41.4 \pm 1.9$ & $12.36 \pm 1.6$ \\
\hline CA-5 & & 10 & 5 & $17 \pm 2$ & $42.3 \pm 1.1$ & $13.72 \pm 1.7$ \\
\hline CA-10 & & 10 & 10 & $15 \pm 1$ & $42.4 \pm 1.3$ & $16.94 \pm 1.8$ \\
\hline CA-15 & & 10 & 15 & $14 \pm 1$ & $42.8 \pm 1.2$ & $17.02 \pm 1.9$ \\
\hline CA-20 & & 10 & 20 & $12 \pm 1$ & $42.9 \pm 1.3$ & $19.11 \pm 1.6$ \\
\hline Control-2 & \multirow{5}{*}{$\begin{array}{l}\text { Croscarmellose } \\
(5 \% \mathrm{w} / \mathrm{v})\end{array}$} & 10 & - & $35 \pm 2$ & $40.5 \pm 2.1$ & $6.48 \pm 0.6$ \\
\hline $\mathrm{CC}-5$ & & 10 & 5 & $33 \pm 1$ & $40.3 \pm 1.5$ & $12.72 \pm 1.5$ \\
\hline CC-10 & & 10 & 10 & $25 \pm 2$ & $40.5 \pm 1.3$ & $14.94 \pm 1.5$ \\
\hline $\mathrm{CC}-15$ & & 10 & 15 & $15 \pm 2$ & $40.4 \pm 1.5$ & $16.99 \pm 1.4$ \\
\hline $\mathrm{CC}-20$ & & 10 & 20 & $13 \pm 1$ & $40.6 \pm 1.2$ & $18.45 \pm 1.5$ \\
\hline Control-3 & \multirow{5}{*}{$\begin{array}{l}\text { Crosspovidone } \\
(5 \% \mathrm{w} / \mathrm{v})\end{array}$} & 10 & - & $38 \pm 3$ & $40.6 \pm 2.0$ & $5.62 \pm 0.7$ \\
\hline $\mathrm{CP}-5$ & & 10 & 5 & $35 \pm 1$ & $40.4 \pm 1.4$ & $11.77 \pm 1.6$ \\
\hline $\mathrm{CP}-10$ & & 10 & 10 & $33 \pm 1$ & $40.9 \pm 1.3$ & $12.66 \pm 2.0$ \\
\hline $\mathrm{CP}-15$ & & 10 & 15 & $19 \pm 1$ & $41.0 \pm 1.3$ & $13.12 \pm 2.1$ \\
\hline CP-20 & & 10 & 20 & $15 \pm 1$ & $41.3 \pm 1.5$ & $15.33 \pm 1.3$ \\
\hline
\end{tabular}


FDTs could not be ascribed to increase in swelling but due to enhanced water transportation and porosity. These findings suggest enhanced water transporting coupled with mechanical strength promoting ability of chitin. The contribution to mechanical strength seems to be due to the ability of chitin to form strong inter and intra molecular hydrogen bonds among the hydroxyl and acetamido groups in solid or liquid state. ${ }^{16,17)}$ In addition, chitin is known to be fibrous in nature. ${ }^{18)}$ Hence, it is logical to expect the combination of its fibrous nature and the ability to form interand intra molecular hydrogen bonds to be responsible for yielding FDTs with low DT even at high TCS. The possible role of chitin in influencing the disintegration time and mechanical strength of FDTs is schematically represented in Fig. 4.

To further investigate effects of chitin on mechanical strength as well as on DT of FDTs, additional FDTs containing croscarmellose sodium $(5 \% \mathrm{w} / \mathrm{v})$ or crospovidone $(5 \% \mathrm{w} / \mathrm{v})$ and various concentrations of chitin $(5-20 \% \mathrm{w} / \mathrm{v})$ instead of CTN-ALG : GLY $(30: 70)$ were prepared (Table 2$)$. The results indicated no significant difference $(p>0.05)$ in DTs of FDTs prepared at $3 \mathrm{~kg}$ TCS as compared to those compressed at $7 \mathrm{~kg}$ TCS, when the concentration of chitin was more than $10 \% \mathrm{w} / \mathrm{w}$, irrespective of the type of super disintegrant. It is evident from Table 2 that the DTs of FDTs containing other superdisintegrant were decreased significantly $(p<0.05)$ at any
TCS when chitin $(>15 \% \mathrm{w} / \mathrm{w})$ was added to their formulation. Hence, the inclusion of chitin in the FDTs containing either superdisintegrant seemed to

Table 2. Effect of Chitin When Present in FDTs Prepared with Different Disintegrant Systems

\begin{tabular}{l|c|c|c|c|c|c}
\hline \hline \multirow{2}{*}{$\begin{array}{c}\text { Formulation } \\
\text { code }\end{array}$} & \multicolumn{2}{|c|}{$\begin{array}{c}\text { Disintegration time (s) of FDTs at } \\
\text { tablet crushing strength (kg) of }\end{array}$} & $\begin{array}{c}\text { Difference* } \\
(p<0.05)\end{array}$ \\
\cline { 2 - 7 } & $3[\mathrm{~A}]$ & 4 & 5 & 6 & $7[\mathrm{~B}]$ & A and B \\
\hline Control-1 & $22 \pm 1$ & $25 \pm 1$ & $35 \pm 2$ & $50 \pm 4$ & $80 \pm 5$ & $\mathrm{~S}$ \\
\hline CA-5 & $20 \pm 1$ & $22 \pm 1$ & $25 \pm 1$ & $26 \pm 1$ & $28 \pm 1$ & NS \\
\hline CA-10 & $18 \pm 1$ & $19 \pm 1$ & $19 \pm 1$ & $19 \pm 1$ & $19 \pm 1$ & NS \\
\hline CA-15 & $16 \pm 1$ & $17 \pm 1$ & $18 \pm 1$ & $18 \pm 1$ & $18 \pm 1$ & NS \\
\hline CA-20 & $16 \pm 1$ & $16 \pm 1$ & $17 \pm 1$ & $17 \pm 1$ & $18 \pm 1$ & NS \\
\hline Control-2 & $38 \pm 1$ & $45 \pm 3$ & $53 \pm 4$ & $69 \pm 3$ & $86 \pm 3$ & S \\
\hline CC-5 & $35 \pm 2$ & $36 \pm 2$ & $38 \pm 2$ & $40 \pm 2$ & $45 \pm 2$ & S \\
\hline CC-10 & $30 \pm 2$ & $30 \pm 2$ & $32 \pm 2$ & $32 \pm 2$ & $35 \pm 1$ & S \\
\hline CC-15 & $20 \pm 2$ & $22 \pm 2$ & $22 \pm 2$ & $22 \pm 2$ & $23 \pm 1$ & NS \\
\hline CC-20 & $18 \pm 1$ & $18 \pm 1$ & $19 \pm 1$ & $19 \pm 1$ & $19 \pm 1$ & NS \\
\hline Control-3 & $40 \pm 1$ & $42 \pm 3$ & $58 \pm 2$ & $75 \pm 5$ & $95 \pm 5$ & S \\
\hline CP-5 & $38 \pm 2$ & $40 \pm 1$ & $45 \pm 2$ & $49 \pm 1$ & $59 \pm 1$ & S \\
\hline CP-10 & $34 \pm 2$ & $35 \pm 1$ & $36 \pm 2$ & $36 \pm 1$ & $37 \pm 2$ & S \\
\hline CP-15 & $22 \pm 2$ & $22 \pm 2$ & $25 \pm 1$ & $25 \pm 1$ & $25 \pm 2$ & NS \\
\hline CP-20 & $20 \pm 1$ & $20 \pm 1$ & $21 \pm 1$ & $21 \pm 1$ & $21 \pm 1$ & NS \\
\hline \multicolumn{1}{|c|}{ Significant difference; NS $=$ No significant difference. * Studentized } \\
\hline
\end{tabular}
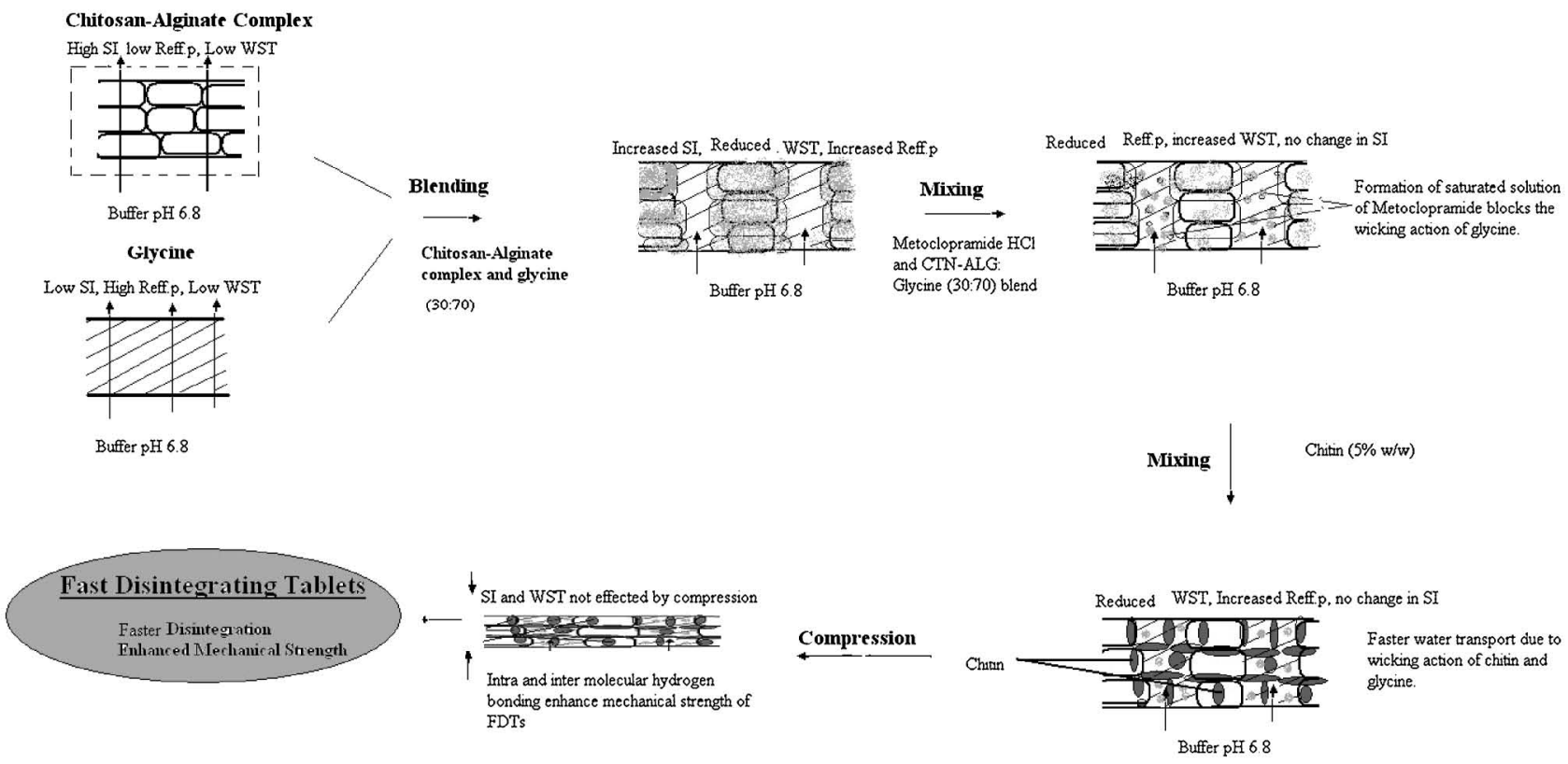

Fig. 4 CTN-ALG: Glycine Disintegrating System for FDTs: Possible Roles of Chitin 
contribute significantly in promoting their disintegration without affecting their mechanical strength.

\section{CONCLUSION}

The present investigation revealed that a disintegration system should contain two main components namely, swelling system with good water absorbing property and tablet strength promoter. If the swelling agent did not have good water absorbing property then its property could be enhanced by adding wetting or wicking agent to constitute a complete swelling system. Therefore, a combination of CTN-ALG : glycine $(30: 70)$ (swelling system) and chitin $(5 \% \mathrm{w} /$ w) (tablet strength promoter) was found to be suitable for preparing FDTs containing water soluble drug metoclopramide $\mathrm{HCl}$ as compared to FDTs containing crospovidone or croscarmellose sodium. Further, chitin was observed to show crucial role in the enhancement of TCS of FDTs without hindering the disintegration time. Hence, it is note worthy to envisage that chitin $(5-10 \% \mathrm{w} / \mathrm{w})$ could be preferably used in FDTs for quick disintegration at higher TCS irrespective of the solubility of drug.

Acknowledgements We gratefully acknowledge Nayan Pharmaceuticals Ltd (Patiala, Punjab, India) and Panacea Biotech Ltd. (Lalru, India) for providing gift samples respectively, of metoclopramide $\mathrm{HCl}$ and crospovidone/croscarmellose sodium.

\section{REFERENCES}

1) Aufmuth K. P., Spec. Publ. Roy, Soc. Chem., 178, 112-115 (1996).

2) Fukami J., Yonemochi B., Yoshihashi Y., Terada K. S., Int. J. Pharm., 310, 101-109 (2006) .

3) Vora N., Rana V., Pharm. Devl. Technol., 13, 1-11 (2008).

4) Goel H., Vora N., Rana V., AAPSPharmSciTech 1530-9932 (2008).
5) Minke R., Blachwell J., J. Mol. Biol., 120, 167 -181 (1978).

6) Rinaudo M., Prog. Polym. Sci., 31, 603-632 (2006).

7) Bruscato F. N., Danti A. G., U.S. Patent 4086335 (1978).

8) Reynolds J. R., “Martindale's Extra Pharmacopoeia," 30th ed., Pharmaceutical Press, London, 1993, pp. 892-894.

9) Ganza-Gonzalez A., Anguiano-Igea S., OteroEspinar F., J., Blanco Mendez I., Eur. J. Pharm. Biopharm., 48, 149-155 (1999) .

10) USP, "Drug Information for the Health Care Professionals," 18th ed., Vol. 1, United States Pharmacopoeial Convention, Rockville, 1998, pp. 2009-2013.

11) Chibowski E., Perea-Carpio R., J. Coll. Interface Sci., 240, 473-479 (2001).

12) Abdelbary G., Eouani C., Prinderre P., Joachim J., Reynier J., Piccerelle P., Int. J. Pharm., 292, 29-41 (2005).

13) Goel H., Rai P., Tiwary A. K., Rana V., Recent Patents on Drug Delivery and Formulation, 2, 258-274 (2008).

14) Fukami J., Ozawa A., Yonemochi B., Yoshihashi Y., Terada K. S., Chem. Pharm. Bull., 53, 1536-1539 (2005).

15) Goel H., Vora N., Tiwary A. K., Rana V., Yakugaku Zasshi, 129, 513-521 (2009).

16) Urbanczyk G., Lipp A., Symonowkz B., Szoslond J., Jeziorny A., Urbaniak J., Domagala W., Dorou K., Wrzosek H., Sztajnowski S., Kowalska S., Sztajnert E., J. Appl. Polym. Sci., 65, 807-819 (1997).

17) Muzzarelli R. A. A., "Chitin," Pergamon Press, London, 1977, p. 209.

18) Saito Y., Okano T., Gaill F., Chanzy H., Putaux J. L., Int. J. Biol. Macromolecules, 28, 81-85 (2000). 